\title{
Research on the Performance Evaluation Method for Cold Chain Logistics of Agriculture Products Based on BP Neural Network Mode
}

\author{
Liu Zheng ${ }^{*}$
}

Department of Economics and Management, Bozhou Teachers College, AnHui, China

\begin{abstract}
Based on BP neural network model, this paper aims at evaluating the performance of cold chain logistics of agriculture products. This paper analyses on the basis of the fresh business' current situation of cold chain logistics, sums up the bottleneck of China's cold chain logistics of agriculture products operation, provides competitive and practical fresh electric cold chain distribution mode in the current cold chain mode of operation and discusses the related problems. The evaluation method is effective to prevent cross contamination of agricultural products, ensure the health, safety and quality of any link from farm to table, and give consumers safe diet to improve people's health level.
\end{abstract}

Keywords: Agriculture products, BP neural network model, cold chain logistics, performance evaluation method.

\section{INTRODUCTION}

With the improvement of the residents' living standards, the demands for fresh fruits and vegetables, anti-season agricultural products are increasing and diverse. Because the fresh agricultural products has characteristics such as strong seasonal, easy to corrosion and difficult to save [1], these characteristics set even higher demands on storage, preservation, transportation, distribution condition and cold chain logistics technology. In recent years, although China's coldchain logistics has developed rapidly, no matter from the aspects of technology or equipment, the infrastructure construction cost of the cold chain logistics is higher, and the investment payback period is longer, leading to the slow development and various aspects is not perfect. "Broken" and repeated freezing phenomena occur frequently, it is difficult to guarantee the freshness and safety of agricultural products.

In recent years, the problem of the food safety problem has caused more and more attention. Food safety incidents occurred frequently caused by the problems of fresh food in the process of production, processing, storage and circulation and its imperfect mismanagement and facilities. Such as Chinese cabbage with Formaldehyde preservation, squeezing the detection of Aflatoxins in peanut oil and some convenient food peroxide value exceeds bid. These food safety problems have been unable to safeguard the legitimate rights and interests of consumers [2], which cause serious damage to the public food safety. Fresh agricultural products is most close to the daily life of consumer, to some extent only guarantee the quality of agricultural products, it can be very good improve the international image of our country on green and healthy. To Solve this problem must be on the research agenda [3].
Organization performance evaluation system in current China mainly on cost, efficiency as the main content, i.e., according to the maximum profit as a standard to measure the performance, also becomes the key to each related organization competition. But such a evaluation method of performance evaluation is a lot of hidden faults, because in addition to quantitative indicators, there are a lot of qualitative indicators is the profit cannot be measured. So to establish the new performance evaluation system, comprehensive and accurately to measure of organizational performance [4], continuously improve business level, enhance the overall strength is imperative. Based on this reality, this article through to the domestic and foreign research status were analysed, and based on predecessor's experiences and lessons, and cold chain logistics distribution centre functions and business processes, based on quality management methods, establish a scientific performance evaluation system [5]. And use of each individual business level and the distribution centre of business process performance as a result, by using the related method of quality management on the performance for further improvement [6].

\section{THE BACKGROUND OF AGRICULTURE PROD- UCTS COLD CHAIN LOGISTICS IN CHINA}

Cold chain logistics, also called low-temperature logistics (LOW TEMPERATURE LOGISTCS) is a special form of logistics, the main object is perishable foods (including raw materials and products), so called foreign generally perishable food cold chain (PERISHABLE FOOD COLD CHAIN). It is with the scientific and technological progress, the development of refrigeration technology, set up, freezing technology is based on the artificial refrigeration technology as a means to production and circulation of convergence, in order to achieve intact to maintain food quality and safety, reduce product loss of a systems engineering. Cold chain logistics of agricultural products referred to herein refers to fruits, vegetables, fish, eggs and other fresh produce, repre- 
sented by purchasing from the origin, processing, storage, transportation, consumer sales until all aspects are in the low-temperature environment, to ensure quality of agricultural products, to reduce the loss of agricultural products, to prevent deterioration and contamination of agricultural products.

Cold chain logistics and general agricultural logistics system at room temperature is compared with the high investment, high demand characteristics. First, the agricultural sectors of the cold chain logistics management and operations require specialized equipment and facilities, construction investment is large, longer-term returns; Second, agricultural production and consumption of cold-chain logistics more decentralized, market supply and demand and price changes large, weather, traffic and other factors are more uncertain, its operation and high energy costs, less stable; third, agricultural requirements of the cold chain, cold chain logistics and the various aspects of the organization and coordination of higher to protect the logistics chain and logistics fewer transactions to ensure timeliness of perishable agricultural products, and strong; fourth, higher agricultural cold chain logistics and information technology requirements for safety of agricultural products quality control or real-time tracking [7].

Cold chain logistics is a special supply chain system that ordered meat, poultry, fish, vegetables, fruits, eggs and other fresh produce are harvested from the origin (or harvesting, slaughter primary finishing) after product processing, storage, transportation, distribution and distribution, in whose process retail and other sectors are always suitable for lowtemperature controlled environment to ensure maximum product quality and quality and safety, prevent pollution and reduce losses. Compared with the general logistics system at room temperature, cold chain logistics have the following characteristics.

Perishable agricultural products have many characteristics, such as it is perishable, with a growth of certain natural cycle, its product is vulnerable to biological and climatic impact on the natural environment, and the quality of raw material quality has a major impact on the final processed product. Cold chain logistics management and operation of all aspects require specialized equipment and facilities, with a large construction investment and longer payback period. In production, agricultural production is seasonal, regional, dispersion; in consumption, agricultural products have small demand elasticity, and are the necessities of life for people with consumer universality and dispersion characteristics. Cold chain logistics of consumption and production is more dispersed, its operation and energy consumption cost higher energy, market supply and demand due to weather, and traffic and other factors are more uncertain, causing larger price changes. Agricultural logistics are in large quantities, varieties and demanding. Different from industrial products, agricultural product is a living animal and plant product, and in the logistics process, it needs not polluting and degenerating. As agriculture is comparatively cheap, bulk, the added value is also low. In order to achieve low-cost operation, cold chain logistics require various aspects of the cold chain have a higher organizational coordination, and reduce the number of transactions to ensure the timeliness of perishable produce strong.

Cold chain logistics have many players in the prenatal, performance, processing, transportation, and marketing and ultimately to the consumer, not only with the existence packing, warehousing and transportation difficulties, but also with high asset specificity, market uncertainty. This requires a higher information technology for safety of agricultural product quality monitoring or real-time tracking.

According to data of "The People's Republic of China 2012 National Economic and Social Development Statistics Bulletin" published on February 22, 2013 by the National Statistics Bureau, our 2012 annual meat production is 83.84 million tons, with an increase of 5.4070 over 2011. Among them, the pork production is 53.35 million tons, with an increase of 5.6070 ; mutton production is 4.01 million tons, with an increase of 2.0070; beef production is 6.62 million tons, with an increase of 2.3070 ; poultry production is 18.23 million tons, with an increase of 6.7070 . At the end of the year, pig's livestock is $474,920,000$, with an increase of 1.6070 ; pig slaughter is $696,280,000$, with an increase of 5.2070. Egg production is 28.61 million tons, with an increase of 1.8070 . Milk production is 37.44 million tons, with an increase of 2.3070. 2012 aquatic products are 59.06 million tons, with an increase of 5.4070 over 2011. Among them, the farmed fish production is $43,050,000$ tons, with an increase of 7.0070; fishing aquatic products are 16.01 million tons, with an increase of 1.3070. Vegetable production has exceeded grain from 2011 and became the first major food crops $[8,9]$.

This had caused a strong demand for cold chain logistics of agricultural products, especially in aquatic products and in-season fruits and vegetables as the representative of highvalue agricultural products for cold chain logistics demanding. Improvement of the lives of our people, enhancement of technology, the rising level and government support promote the formation of the cold chain logistics market, and further promote the development of the cold chain logistics market.

\section{THE PERFORMANCE EVALUATION USING BP NEURAL NETWORK}

Here the use of the BP neural network model with multiinput and single-output as building performance evaluation, the topology is shown in Fig. (1).



Fig. (1). The three layers bop neural network topology. 
Non-linear relationship between the output and input between each node is described as sigmoid function, that is:

$$
f(x)=\frac{1}{1+e^{-x}}
$$

BP network learning and training is a back propagation and correction process. The total error is defined samples of actual output and the desired output function is:

$$
E_{\text {fofaj }}=\frac{1}{2} \sum_{j=1}^{n}\left(b_{j}-b_{j}\right)^{2}
$$

Each index can score from reviewer's subjective scoring method after obtaining. The data to be using equation (3) is normalized.

$$
\overline{x_{i}}=\frac{x_{i}-b_{i}}{a_{i}-b_{i}}
$$

Where $\mathrm{Xi}$ and $\mathrm{Xj}$ respectively, the $\mathrm{i}$-the index and the actual value Standard value; air, bi are the maximum, minimum, the $\mathrm{i}$-the index. Known evaluation indexes $\mathrm{m}, \mathrm{n}$ hidden layer nodes depending Problems and experimental data to determine, you can also experience the value of the formula (4) the decision.

$$
n=\log _{2} m(4)
$$

Hidden node output is calculated as follows:

$$
h_{j}=f\left(\sum_{i=1}^{m} w_{i j} x_{i}-\theta_{j}\right)
$$

where $\theta \mathrm{j}$ is defined as the threshold value for hidden node.

The output of the output node is calculated as follows:

$$
f\left(\sum_{i=1}^{m} w_{i} x_{i}-\theta_{j}\right)=f\left(f\left(\theta_{j}\right)\right)
$$

where in $\theta$ is an output node threshold.

Using genetic algorithm to train the neural network can be used in binary code, code String value from the hidden layer to the input layer connection weights win, hidden layer and output layer connection Weights to, hidden layer threshold $\theta \mathrm{j}$, the output layer threshold $\theta$. So connected together to form into a long string (the string corresponding to each position of a group of network weights and threshold Value), constitutes an individual. It can generate an initial population of $\mathrm{N}$ individuals.

Guiding the evolutionary process toward the region of space may contain the best individual conduct. Suitable Select the function should have a great impact on the training results. This paper fitness Function uses a calculation error of the neural network (see equation 6), and the error. Always cut along the neural network output error fewer search direction, the convergence target is the minimum output error.

To speed up convergence rate of BP algorithm and improve accuracy and effectiveness of the case retrieval and case maintenance overall design, using genetic algorithm optimize the global search ability, searching the global opti- mum point nearby; Then use BP algorithm with strong partial optimization, start from this point, searching locally, thus achieving the goal of network training. Fig. (2) is the combination models of the genetic algorithm and neural network.

Particular way is, firstly code the model's initial weight values and threshold, constitute the initial population, then generate the next generation population with the genetic algorithm, decode the best individuals of the population we obtain the weight, threshold and make evaluation; If it meets the design requirements, then output the optimal weights and threshold, otherwise proceed to the operation of genetic algorithm until get the best individual of a generation population on genetic algorithm, output weights and the threshold value, which is the weight and threshold value on global optimum of network, and then they are assigned to the BP network for final training.

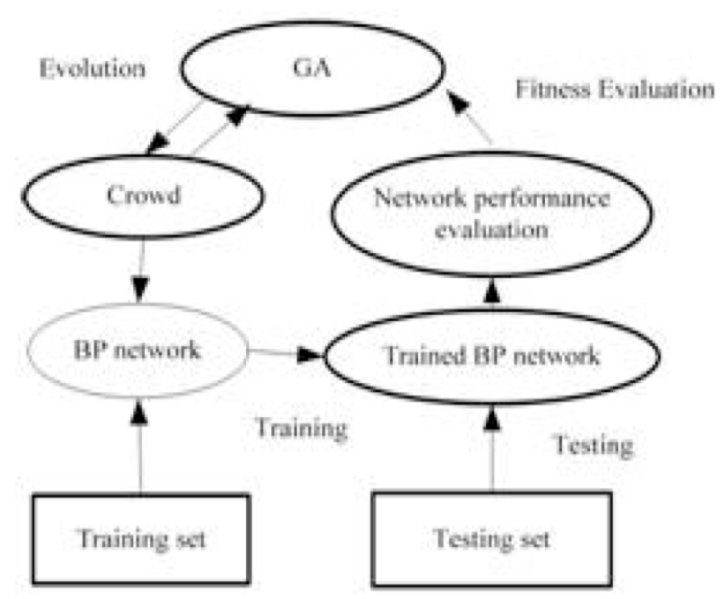

Fig. (2). Composite pattern between gas and bop network.

The BP neural network is widely used mainly for the following advantages: giant parallel distribution makes the processing speed greatly; the distribution of knowledge information is stored in network connection and threshold that has strong fault-tolerance. Although BP network model has many advantages in all aspects, but also has some deficiencies: from the view of mathematics, it is a nonlinear optimization problem and inevitably there exists local minimum points; study algorithm is very slow; the selection of network hidden nodes with great blindness, and there are no empirical theoretically instructions and etc.. Therefore, these disadvantages greatly limit the application and promotion of the BP neural network. The paper establishes the highway project construction risk prediction model, mainly using genetic algorithms and BP network combination to improve the performance of BP network, on the basis of series of improvement such as the sample data pretreatment, optimize network hidden nodes, introducing momentum, adaptive adjustments network parameters.

Genetic algorithm is a search algorithm based on natural selection and genetic mechanisms for groups, and simulates the course of reproduction, and the interbreeding in the process of a natural and genetic selection. Using genetic algorithm, every possible solution is coded as "a chromosome", namely the individual, a number of individuals form groups (all possible solutions). Genetic algorithm is the process of 




Fig. (3). Performance evaluation system of cold chain based on BP network.

evolution generational group which is the community of a feasible solution (LIU Jie, GAN Xu-sheng, 2008).

The evaluation system can be constructed as Fig. (3).

\section{CONCLUSION}

This paper starts from the essence of performance evaluation of cold chain, constructs the performance evaluation index system of cold chain, the index system has the characteristic of performance evaluation of supply chain and requirements of low-temperature of cold chain itself, and put forward that Decision-making capacity was one of the most important evaluation in performance evaluation index system firstly, then using BP neural network to construct the performance evaluation model of cold chain. This evaluation model can reduce human factors during evaluation process effectively, and improve the reliability and objectivity of the evaluation. There are still some shortages in paper. Firstly, the performance evaluation index system of cold chain consults most of the SCOR evaluation index system. Because of the high demand of time and temperature to cold product, the rationality of the index system also needs further proof, especially in practical application. Secondly, BP neural network model needs a certain study sample, the quality and quantity of study sample were greatly affected learning ability of neural network, so, choose a proper study sample is a very difficult and complex thing, and BP neural network can be in local optimal during studying and training process easily, which constrained the accuracy of evaluation.

\section{CONFLICT OF INTEREST}

The author confirms that this article content has no conflict of interest.

\section{ACKNOWLEDGEMENTS}

This work is supported by the Key Project of Guangxi Social Sciences, China (No. gxsk201424), the Education Science fund of the Education Department of Guangxi, China (No. 2014JGA268), and Guangxi Office for Education Sciences Planning, China (No. 2013C108).

\section{REFERENCES}

[1] C. Zhi-gao, "Application of genetic algorithm and BP neural network in GDP forecasts, "Computer and Digital Engineering, vol. 6, no. 2 pp. $245-255,2009$.

[2] L. Jie, and G. Xu-sheng, "Optimum design of self-adaptive wavelet neural networks based on hybrid hierarchy genetic algorithm," Fire Control and Command Control, vol. 2, pp. 12-22, 2008.

[3] H.F. Mo, A.Y. Gu, X.Z. Zhang, and J.C. Zhang, "Research on a method of BP neural network in water quality evaluation, " Control Engineering of China, vol. 2, pp. 9-10, 2004.

[4] Z.G. Niu, H.W. Zhang, and H.B. Liu, "Application of neural network to prediction of coastal water quality,"Journal of Tianjin Polytechnic University, vol. 3, pp. 89-92. 2006.

[5] P.J. Jones, "Functional food development: concept to reality, "Trends in Food Science \& Technology, vol. 2, pp. 387-390, 2007.

[6] R. Ryder, "Procurement best practice in the food industry: supplier clustering as a source of strategic competitive advantage," Supply Chain Management: An International Journal Supply Chain Management: An International Journal, vol. 3, pp. 164-171, 2003. 
[7] J. Shu, "Using neutral network model to predict water quality, "North Environment, vol. 3, pp. 44-46, 2006.

[8] Q.H. Wang, "Improvement on BP algorithm in artificial neural network," Journal of Qinghai University, vol. 3, pp. 82-84. 2004.
[9] Z. Bin, and W. Gung-ho, "Cooperation of artificial neural networks and improved genetic algorithms for solving," Computer Engineering and Applications, vol. 4, pp. 35-37,2011.

Received: June 10,2015

Revised: July 29,2015

Accepted: August 15, 2015

(C) Liu Zheng; Licensee Bentham Open.

This is an open access article licensed under the terms of the (https://creativecommons.org/licenses/by/4.0/legalcode), which permits unrestricted, noncommercial use, distribution and reproduction in any medium, provided the work is properly cited. 